\title{
Economic Analysis: Randomized, Placebo-Controlled Clinical Trial of Dutasteride in Men at High Risk for Prostate Cancer
}

Costel Chirila ${ }^{1 *}$, Stephanie R. Earnshaw ${ }^{1}$, Libby Black², Cheryl McDade ${ }^{1}$, Neil Roskell ${ }^{3}$, Paul Shannon $^{3}$, Francesco Montorsi ${ }^{4}$ and Gerald L. Andriole $^{5}$

${ }^{1}$ RTI Health Solutions, PO Box 12194, Research Triangle Park, NC 27709, USA

${ }^{2}$ GlaxoSmithKline, Five Moore Drive, Research Triangle Park, NC 27709, USA

${ }^{3}$ RTI Health Solutions, 2nd Floor, The Pavilion, Towers Business Park, Wilmslow Road, Didsbury, Manchester, M20 2LS, United Kingdom

${ }^{4}$ Universitá Vita Salute San Raffaele, Via Olgettina 60, 20132 Milan, Italy

${ }^{5}$ Division of Urology, Washington University School of Medicine, Barnes-Jewish Hospital, Siteman Cancer Center, 4960 Children's Place, Campus Box 8242, St. Louis, MO 63110

\begin{abstract}
Objective: Given the economic burden of prostate cancer (PCa), a PCa risk-reduction medication would be desirable. A within-trial economic analysis of the Reduction by Dutasteride of Prostate Cancer Events (REDUCE) study was performed.

Methods: REDUCE, a 4-year, randomized, double-blind, placebo-controlled, parallel-group clinical trial, compared efficacy and safety of dutasteride $0.5 \mathrm{mg}$ daily and placebo to reduce the risk of PCa in men at increased risk. Resource use was prospectively collected; costs from standard costing sources were applied. Utilities were obtained from published literature. Relative risks and Wilcoxon rank sums were used to examine differences between treatments.

Results: Placebo patients were at significantly higher risk $(P<0.05)$ for concomitant medication use; and health care visits related to surgical procedures, unscheduled biopsies, acute urinary retention, urinary tract infections, or macroscopic hematuria. Total costs were significantly lower $(P<0.001)$ in dutasteride patients $(\$ 1300 ; 95 \%$ confidence interval: \$806, \$1 795). Incremental cost per quality-adjusted life-year (QALY) was \$26 516; cost per PCa case avoided was $\$ 19$.

Conclusions: During the 4-year trial period, men at increased risk for PCa receiving dutasteride incurred fewer health care costs than men receiving placebo, which helped offset dutasteride costs. Dutasteride was good value for money.
\end{abstract}

Keywords: Benign prostatic hyperplasia; Prostate cancer; Resource use; Cost-effectiveness analysis; Economics

Abbreviations: 5ARI: 5-alpha reductase inhibitors; AUR: Acute urinary retention; $\mathrm{BPH}$ : Benign prostatic hyperplasia; $\mathrm{CI}$ : Confidence interval; ICER: Incremental cost-effectiveness ratios; PCa: Prostate cancer; PSA: Prostate-specific antigen; QALY: Quality-adjusted lifeyear; REDUCE: Reduction by Dutasteride of Prostate Cancer Events (clinical trial); US: United States; UTI: Urinary tract infection

\section{Introduction}

Prostate cancer $(\mathrm{PCa})$ is one of the most common cancers in American men and the second leading cause of cancer death [1]. An estimated 1 in 6 men will be diagnosed with PCa during their lifetime, and 1 in 36 men will die of PCa [1]. Medical expenditures for PCa were estimated to be $\$ 11.85$ billion in 2010 and projected to reach $\$ 16.34$ billion in 2020 (in 2010 dollars) [2].

Given this burden, medication to reduce the risk of PCa could provide economic and quality-of-life benefits. In recent years, the use of 5-alpha reductase inhibitors (5ARIs) has been studied for PCa risk reduction. Specifically, finasteride has been shown to reduce the incidence of PCa by $24.8 \%$ (95\% confidence interval [CI]: 18.6\%-30.6\%; $P<0.001$ ) in men with serum prostate-specific antigen (PSA) $<3.0 \mathrm{ng} /$ $\mathrm{mL}$ in the Prostate Cancer Prevention Trial [3]. In a recent clinical trial, the Reduction by Dutasteride of Prostatic Cancer Events (REDUCE), dutasteride $(0.5 \mathrm{mg} /$ day $)$ was shown to reduce the risk of PCa by $22.8 \%$ (95\% CI: $15.2 \%-29.8 \% ; P<0.001)$ compared with placebo in men with a negative biopsy and PSA $>2.5 \mathrm{ng} / \mathrm{mL}$ at baseline [4]

Previous analyses have examined the potential cost-effectiveness of a chemoprevention agent for prostate cancer. Because of incomplete information at the time, these analyses used decision analytic techniques, such as Markov models, to compile data from multiple sources and extrapolate the potential impact on costs and outcomes that might be seen over a man's remaining lifetime [5-11]. Within the REDUCE study, data on resource use were collected along side of the clinical data. This study was an economic analysis of resource use data from the REDUCE clinical trial, comparing dutasteride with placebo in men at increased risk for PCa in the first 4 years of drug administration.

*Corresponding author: Costel Chirila, RTI Health Solutions, PO Box 12194, Research Triangle Park, NC 27709, USA, Tel: +1.919.541.8083; Fax: +1.919.541.7222; E-mail: cchirila@rti.org

Received November 10, 2011; Accepted December 09, 2011; Published December 11, 2011

Citation: Chirila C, Earnshaw SR, Black L, McDade C, Roskell N, et al (2011) Economic Analysis: Randomized, Placebo-Controlled Clinical Trial of Dutasteride in Men at High Risk for Prostate Cancer. J Cancer Sci Ther S3:004. doi:10.4172/1948-5956.S3-004

Copyright: (C) 2011 Chirila C, et al. This is an open-access article distributed under the terms of the Creative Commons Attribution License, which permits unrestricted use, distribution, and reproduction in any medium, provided the original author and source are credited. 


\section{Materials and Methods}

\section{REDUCE Study Design}

The REDUCE clinical trial was a 4-year, phase 3, international, multicenter, randomized, double-blind, placebo-controlled, parallel group study to evaluate the safety and efficacy of oral, once-daily 0.5 $\mathrm{mg}$ dutasteride in reducing the risk of biopsy-detectable PCa in men aged 50 to 60 years with PSA of 2.5 to $10 \mathrm{ng} / \mathrm{mL}$ or in men aged 60 years or older with PSA of 3.0 to $10 \mathrm{ng} / \mathrm{mL}$ and with a single negative prostate biopsy in the prior 6 months and prostate volume of $80 \mathrm{cc}$ or less [4]. The trial randomized 8,231 men to receive dutasteride or placebo. Patients underwent transrectal ultrasound-guided biopsies at 2 and 4 years. The primary endpoint was biopsy-detectable PCa. The REDUCE clinical trial was approved by the institutional review boards at each research site, and all participants provided written informed consent [4]. This analysis was performed using de-identified data (i.e., all researchers were blinded to any identifying information).

\section{Resource Use}

Resource use data were collected during the trial within case report forms. For our analysis, we included only resource use related to $\mathrm{PCa}$, benign prostatic hyperplasia (BPH), or other conditions believed to be affected by the use of a 5ARI. Resource use included concomitant medications and health care visits associated with surgical and nonsurgical procedures, unscheduled biopsies, urinary tract infections (UTIs), acute urinary retention (AUR), and macroscopic hematuria and hematospermia episodes unrelated to trial-specified biopsies.

Concomitant medications included those related to the conditions previously mentioned-chemotherapies, hormone therapies, antibiotic therapy for treating UTI, and alpha-blocker use for treating $\mathrm{BPH}$-as well as concomitant medications used to treat significant adverse events due to dutasteride use (e.g., impotence, decreased libido, and ejaculation disorders). A clinician was consulted on concomitant medications included in our analysis. All procedures and concomitant medication classes considered are presented in the online appendix.

\section{Costs}

Direct medical costs were obtained from the payer perspective. All costs were reported in 2010 United States (US) dollars. Details of how per-patient direct costs were calculated are explained in the online appendix.

\section{Inpatient Costs}

Inpatient costs per day for surgical and nonsurgical procedures, UTI, AUR, and macroscopic hematuria and hematospermia were obtained from the Healthcare Cost and Utilization Project Nationwide Inpatient Sample [12]. Charges obtained from this database were converted to costs using published costs-to-charge ratios [13].

\section{Outpatient Costs}

Outpatient visits, outpatient procedures, unscheduled biopsies, and drug administrations were assigned a Current Procedural Terminology code from the Current Procedural Terminology and Healthcare Common Procedure Coding System [14]. All codes were verified by a clinician. Costs were obtained from the Resource-Based Relative Value Scale [15].

\section{Concomitant Medications Costs}

Wholesale drug acquisition costs were obtained from the 2010
Red Book for Windows [16]. Generic drugs and/or lowest-cost drugs were used when branded medications were not specified. For hormone therapies not available in the US, we used the average US costs of hormone therapies within the REDUCE trial.

The objective of the resource use and cost analysis was to understand the impact on other medical costs when using dutasteride. As a result, the cost of dutasteride was excluded from this analysis. However, the cost of dutasteride was included in the cost-effectiveness analysis. Dutasteride's wholesale acquisition cost for the cost-effectiveness analysis was $\$ 3.62$ per day [16].

\section{Utility and Quality of Life}

To calculate quality-adjusted life-years (QALYs) and perform cost-utility analyses, we obtained utility weights from the published literature [17-19] and applied these to the men within the REDUCE trial according to health status. (Data required to calculate utilities were not collected within REDUCE.) Specifically, over the course of a man's involvement in the trial, he was designated as being in one of the following health states: healthy with no PCa or BPH, BPH but no PCa, high-grade or low-grade PCa, or death. A man's QALYs were decremented if adverse events, such as ejaculatory dysfunction and impotence, UTIs, AURs, and BPH-related surgeries, occurred. In particular, men on dutasteride incurred a utility decrement due to the sexual dysfunction AEs. Since utilities for high-grade and low-grade tumors consider AEs that may occur due to PCa treatment, utility decrements for AEs due to PCa treatment were not considered. Men with $\mathrm{BPH}$ who were taking dutasteride or an alpha-blocker were assumed to incur an improvement in symptoms. The utilities and utility decrements obtained from the published literature are presented in Table 1.

\section{Statistical Analysis}

The analysis population within this study, called the biopsy population, consisted of patients in the efficacy population (as defined in [4]) who had at least one post-baseline biopsy. A resource use event was included in the economic analysis if it happened during the trial period. Inclusion criteria and date imputation rules are presented in the online appendix.

Resource use was analyzed as categorical variables (i.e., whether a patient used a specific resource or not). The number and proportion of patients using the resource and 95\% CIs were summarized for each treatment group. Statistical comparisons were made between treatment groups (i.e., placebo vs. dutasteride) using $95 \%$ CIs of relative risks. A resource use with a lower-bound $95 \%$ CI of relative risk greater than 1 means that the risk for having a resource use is significantly higher for patients in the placebo group than for patients in the dutasteride group.

Costs were analyzed as continuous variables; we estimated means and standard deviations among each resource use category for each treatment group since arithmetic mean cost is more appropriate [20]. We also calculated mean differences (i.e., placebo vs. dutasteride) and 95\% CIs. However, because resource use distribution and therefore cost distribution can be heavily skewed, we preferred to use a nonparametric test, Wilcoxon rank sum, to test the null hypothesis that the cost distributions in the two treatment groups were the same. The cost distribution is significantly lower (or higher) in the dutasteride group than in the placebo group if the observed rank sum in the dutasteride group is less (or greater) than the expected rank sum. A test result was declared statistically significant if the $P$ value was less than 0.05 . No adjustments were made for multiple comparisons since this correction 
Citation: Chirila C, Earnshaw SR, Black L, McDade C, Roskell N, et al. (2011) Economic Analysis: Randomized, Placebo-Controlled Clinical Trial of Dutasteride in Men at High Risk for Prostate Cancer. J Cancer Sci Ther S3:004. doi:10.4172/1948-5956.S3-004

Page 3 of 8

would increase the frequency of type II errors (i.e., false negatives) [21]. Analyses were performed using SAS, version 9.1 (SAS Institute, Inc., Cary, North Carolina).

\section{Cost-effectiveness Ratios}

Cost-effectiveness and cost-utility analyses were performed. The incremental cost-effectiveness ratios (ICERs) of incremental cost per PCa case avoided [5] and incremental cost per QALY gained were calculated. ICERs were calculated as the ratio of the difference in average total costs between the two treatment groups and the difference in average effectiveness between the two treatment groups. Dutasteride was considered cost-effective if the incremental cost per QALY gained was $\$ 50000$ or less [22-24].

\section{Sensitivity Analyses}

We performed sensitivity analyses by running the resource use and cost analyses in other population subgroups defined by geographic region and baseline PSA. These analyses were performed to understand the effect that methodological assumptions had on the results. All populations are described in Table 2, together with the respective patient numbers, by treatment group.

To consider uncertainty due to sampling variation surrounding the estimate of the ICERs, we ran 1000 bootstrap replications to calculate the median and bootstrapped 95\% percentiles of the ICERs [25]. A scatter plot and cost-effectiveness analysis curve were constructed [26].

\section{Results}

The biopsy population consisted of 3305 patients in the dutasteride group and 3424 patients in the placebo group (Table 2). Date imputation across treatment groups was similar, where $25 \%$ of patients had imputed dates for concomitant medications and $4 \%$ of patients had imputed dates for nonconcomitant medication resources. PCa occurred in 599 patients in the dutasteride group and 782 patients in the placebo group.

\section{Resource Use}

Table 3 presents the results of the resource use analysis. Overall, the largest resource use categories were concomitant medication use (27\%) and unscheduled biopsies (12\%).

Table 1: Utility Weights and Utility Decrements for Calculating Quality-Adjusted Life-years.

\begin{tabular}{|c|c|c|}
\hline Parameter & Utility Value & Sources/Assumptions \\
\hline Age-specific utilities & & [19] \\
\hline $30-39$ years & 0.940 & \\
\hline $40-49$ years & 0.930 & \\
\hline $50-59$ years & 0.920 & \\
\hline $60-69$ years & 0.910 & \\
\hline $70-79$ years & 0.910 & \\
\hline $80+$ years & 0.880 & \\
\hline \multicolumn{3}{|l|}{ Health state-specific utilities } \\
\hline Healthy men: no PCa or BPH & 1.000 & Assumption \\
\hline $\mathrm{BPH}$ & 0.963 & [17] \\
\hline PCa: high-grade cancer ${ }^{a}$ & 0.760 & [18] \\
\hline PCa: low-grade cancera & 0.840 & [18] \\
\hline Death & 0.000 & Assumption \\
\hline \multicolumn{3}{|l|}{ Utility decrements/improvements } \\
\hline BPH symptom improvement due to use of dutasteride & 0.018 & {$[17]$} \\
\hline AUR & 0.003 & [17] \\
\hline BPH-related surgery & 0.0005 & {$[17]$} \\
\hline Ejaculatory dysfunction & 0.007 & {$[17]$} \\
\hline Impotence & 0.029 & [17] \\
\hline Hospitalization due to UTI & 0.00058 & {$[17]$} \\
\hline
\end{tabular}

AUR = acute urinary retention; $\mathrm{BPH}=$ benign prostatic hyperplasia; $\mathrm{PCa}=$ prostate cancer; $\mathrm{UTI}=$ urinary tract infection

aUtilities for high-grade and low-grade tumors consider adverse events that may occur due to PCa treatment.

Table 2: Analysis Populations ${ }^{a}$.

\begin{tabular}{|c|c|c|c|}
\hline Population & Description & Dutasteride $(\mathrm{N}=4015)$ & Placebo $(\mathrm{N}=4126)$ \\
\hline Biopsy & $\begin{array}{l}\text { Patients in the REDUCE trial who had a negative prostate biopsy upon entry } \\
\text { into the study, who received at least } 1 \text { dose of study treatment, and who had } \\
\text { at least } 1 \text { post-baseline biopsy }\end{array}$ & 3305 & 3424 \\
\hline North America & $\begin{array}{l}\text { All patients in biopsy population who were participating through } \\
\text { investigational sites in the US, Canada, and Puerto Rico }\end{array}$ & $\begin{array}{c}810 \\
(24.5 \%)\end{array}$ & $\begin{array}{c}844 \\
(24.6 \%)\end{array}$ \\
\hline Baseline PSA $<4.9 \mathrm{ng} / \mathrm{mL}$ & All patients in the biopsy population who had baseline PSA $<4.9 \mathrm{ng} / \mathrm{mL}$ & $\begin{array}{c}1095 \\
(33.1 \%)\end{array}$ & $\begin{array}{c}1173 \\
(34.3 \%)\end{array}$ \\
\hline Baseline PSA $\geq 4.9$ and $<6.8 \mathrm{ng} / \mathrm{mL}$ & $\begin{array}{l}\text { All patients in the biopsy population who had a baseline PSA } \geq 4.9 \text { and }< \\
6.8 \mathrm{ng} / \mathrm{mL}\end{array}$ & $\begin{array}{c}1121 \\
(33.9 \%)\end{array}$ & $\begin{array}{c}1138 \\
(33.2 \%)\end{array}$ \\
\hline Baseline PSA $\geq 6.8 \mathrm{ng} / \mathrm{mL}$ & All patients in the biopsy population who had a baseline PSA $\geq 6.8 \mathrm{ng} / \mathrm{mL}$ & $\begin{array}{c}1086 \\
(32.9 \%)\end{array}$ & $\begin{array}{c}1105 \\
(32.3 \%)\end{array}$ \\
\hline
\end{tabular}

PSA = prostate-specific antigen; REDUCE = Reduction by Dutasteride of Prostate Cancer Events; US = United States.

apatients in the population subgroups defined by baseline PSA do not total to $100 \%$ because 3 and 8 patients in the dutasteride and placebo groups, respectively, had missing baseline PSA measures. 
Citation: Chirila C, Earnshaw SR, Black L, McDade C, Roskell N, et al. (2011) Economic Analysis: Randomized, Placebo-Controlled Clinical Trial of Dutasteride in Men at High Risk for Prostate Cancer. J Cancer Sci Ther S3:004. doi:10.4172/1948-5956.S3-004

Page 4 of 8

Compared with patients in the dutasteride group, patients in the placebo group were at significantly higher risk for incurring use of concomitant medication (including alpha-blocker use); and health care visits for treating surgical procedures, unscheduled biopsies, UTIs, AURs, or macroscopic hematuria (Table 3).

\section{Costs}

Concomitant medication (40\%) and surgical (42\%) costs made up the majority of the total costs incurred (Figure 1). Surgical costs were the major contributor to total costs, although they occurred in only $4 \%$ of patients during the trial period. These proportions were similar between treatment groups.

Total costs, excluding the study drug cost, were significantly lower in the dutasteride group (mean difference of $\$ 1300 ; 95 \%$ CI: \$806, \$1 795) (Table 4). Patients in the dutasteride group incurred significantly lower costs for concomitant medication use (including alpha-blocker use); and health care visits for treating surgical procedures, unscheduled biopsies, UTIs, AURs, or macroscopic hematuria. According to the Wilcoxon rank sum test, patients in the dutasteride group incurred significantly lower costs for concomitant medications and macroscopic hematuria despite mean total costs being higher for this group than for the placebo group. This counterintuitive result is possible due to skewness of cost distribution.

\section{Cost-effectiveness}

Over the 4-year period of the trial, the mean acquisition cost of dutasteride among men in the dutasteride group was $\$ 4733$. Thus, the acquisition cost of dutasteride was not fully offset by reductions in other medical costs. However, men in the dutasteride group did accrue 0.13 more QALYs than men in the placebo group (3.26 vs. 3.13). As a result, the use of dutasteride to reduce the risk of PCa was cost-effective, with an incremental cost per QALY of \$26 516 (Table 5). The incremental cost per PCa avoided was calculated as $\$ 19$ (Table 5).

\section{Sensitivity Analysis}

Differences in resource use within the subgroup populations were found to be similar to the differences observed for the biopsy population. The difference in mean total costs was found to be

Table 3: Number and Proportion of Resource Events or Procedures by Treatment Group ${ }^{\text {. }}$

\begin{tabular}{|c|c|c|c|c|c|c|}
\hline \multirow{2}{*}{\begin{tabular}{|l} 
Patient Numbers \\
Resource \\
\end{tabular}} & \multicolumn{2}{|r|}{$\begin{array}{c}\text { Dutasteride } \\
(\mathrm{N}=3,305)\end{array}$} & \multicolumn{2}{|r|}{$\begin{array}{l}\text { Placebo } \\
(\mathrm{N}=3,424)\end{array}$} & \multicolumn{2}{|c|}{ Relative Risk } \\
\hline & $\mathbf{n}$ & Percentage $(95 \% \mathrm{Cl})$ & $\mathbf{n}$ & Percentage $(95 \% \mathrm{CI})$ & Estimate & $95 \% \mathrm{Cl}$ \\
\hline Concomitant Medications & 841 & $25(24,27)$ & 994 & $29(28,31)$ & 1.14 & $1.05,1.23$ \\
\hline Alpha-blockers & 713 & $22(20,23)$ & 862 & $25(24,27)$ & 1.17 & $1.07,1.27$ \\
\hline \multicolumn{7}{|l|}{ Health Care Visits } \\
\hline Surgical procedures & 60 & $2(1,2)$ & 188 & $5(5,6)$ & 3.02 & $2.27,4.03$ \\
\hline Nonsurgical procedures & 5 & $0(0,0)$ & 12 & $0(0,1)$ & 2.32 & $0.82,6.57$ \\
\hline Unscheduled biopsies & 322 & $10(9,11)$ & 470 & $14(13,15)$ & 1.41 & $1.23,1.61$ \\
\hline UTI & 186 & $6(5,6)$ & 299 & $9(8,10)$ & 1.55 & $1.30,1.85$ \\
\hline AUR & 53 & $2(1,2)$ & 230 & $7(6,8)$ & 4.19 & $3.12,5.62$ \\
\hline Macroscopic hematuria & 114 & $3(3,4)$ & 171 & $5(4,6)$ & 1.45 & $1.15,1.83$ \\
\hline Macroscopic hematospermia & 43 & $1(1,2)$ & 35 & $1(1,1)$ & 0.79 & $0.50,1.22$ \\
\hline
\end{tabular}

AUR = acute urinary retention; $\mathrm{Cl}=$ confidence interval; UTI = urinary tract infection.

${ }^{a}$ Table presents the proportions of patients within each treatment group who experience at least one episode of each resource.

AUR = acute urinary retention; $\mathrm{UTI}=$ urinary tract infection

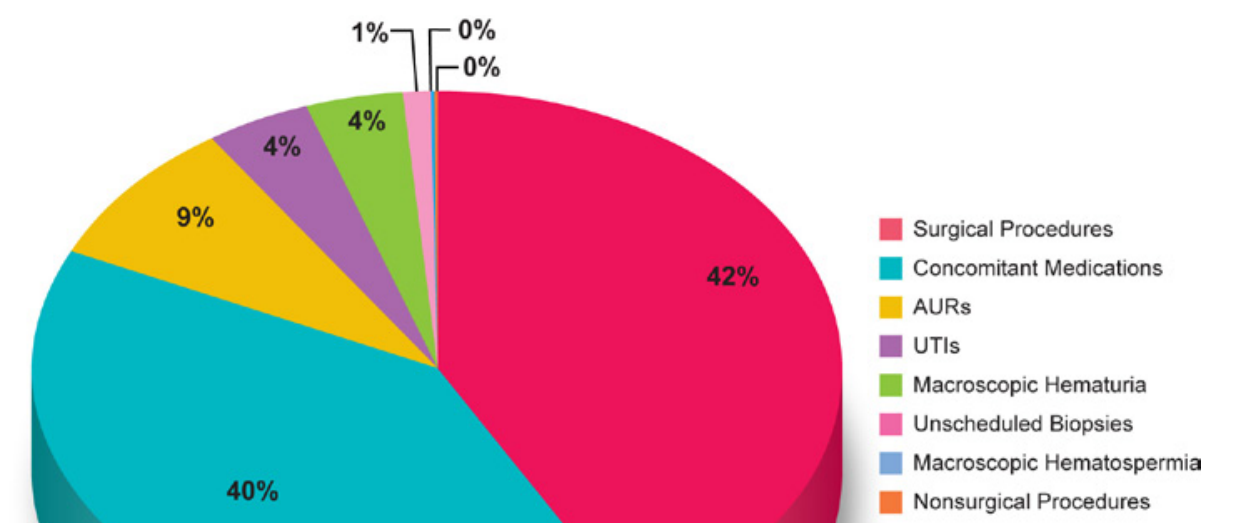

Figure 1: Breakdown of Total Costs. 
Table 4: Summary of Health Care Costs by Treatment Group.

\begin{tabular}{|c|c|c|c|c|c|}
\hline \multirow[b]{2}{*}{ Resource } & \multirow{2}{*}{$\begin{array}{c}\text { Dutasteride } \\
(\mathrm{N}=3305) \\
{\text { Mean }(\mathrm{SD})^{\mathrm{b}}}\end{array}$} & \multirow{2}{*}{$\begin{array}{c}\text { Placebo } \\
(\mathrm{N}=3424) \\
\text { Mean (SD) }\end{array}$} & \multicolumn{2}{|c|}{ Mean Difference $^{a}$} & \multirow{2}{*}{$\begin{array}{c}\begin{array}{c}\text { Wilcoxon Rank } \\
\text { Sum }\end{array} \\
P \text { Value }\end{array}$} \\
\hline & & & Estimate & $95 \% \mathrm{Cl}$ & \\
\hline Total & $\$ 1877(\$ 7098)$ & $\$ 3177(\$ 12707)$ & $\$ 1300.40$ & $\$ 806.15-\$ 1794.66$ & $<0.001$ \\
\hline Concomitant Medications & $\$ 1028(\$ 3078)$ & $\$ 1004(\$ 2666)$ & $-\$ 24.28$ & $-\$ 161.75$ to $\$ 113.19$ & 0.005 \\
\hline Alpha-blockers & $\$ 818(\$ 2110)$ & $\$ 830(\$ 2092)$ & $\$ 11.28$ & $-\$ 89.15$ to $\$ 111.71$ & 0.004 \\
\hline \multicolumn{6}{|l|}{ Health Care Visits } \\
\hline Surgical procedures & $\$ 539(\$ 5358)$ & $\$ 1576(\$ 10164)$ & $\$ 1036.66$ & $\$ 646.34$ to $\$ 1426.97$ & $<0.001$ \\
\hline Nonsurgical procedures & $\$ 0(\$ 4)$ & $\$ 6(\$ 311)$ & $\$ 5.61$ & $-\$ 4.99$ to $\$ 16.21$ & 0.104 \\
\hline Unscheduled biopsies & $\$ 23(\$ 74)$ & $\$ 32(\$ 86)$ & $\$ 9.16$ & $\$ 5.32$ to $\$ 12.99$ & $<0.001$ \\
\hline UTI & $\$ 69(\$ 965)$ & $\$ 150(\$ 2085)$ & $\$ 81.22$ & $\$ 3.12$ to $\$ 159.32$ & $<0.001$ \\
\hline AUR & $\$ 115(\$ 1802)$ & $\$ 318(\$ 2707)$ & $\$ 203.55$ & $\$ 93.24$ to $\$ 313.85$ & $<0.001$ \\
\hline Macroscopic hematuria & $\$ 96(\$ 1501)$ & $\$ 91(\$ 1189)$ & $-\$ 5.30$ & $-\$ 69.89$ to $\$ 59.29$ & 0.001 \\
\hline Macroscopic hematospermia & $\$ 7(\$ 352)$ & $\$ 0(\$ 4)$ & $-\$ 6.21$ & $-\$ 18.01$ to $\$ 5.58$ & 0.336 \\
\hline
\end{tabular}

$\mathrm{AUR}=$ acute urinary retention; $\mathrm{Cl}=$ confidence interval; $\mathrm{SD}=$ standard deviation; $\mathrm{UTI}=$ urinary tract infection.

${ }^{\text {a }}$ Mean difference $=$ placebo costs - dutasteride costs.

${ }^{b}$ Median cost was zero for all resource use categories; inter-quartile range was zero for all resource use categories except concomitant medications.

Table 5: Baseline and Bootstrapped Incremental Cost-effectiveness Ratios.

\begin{tabular}{|c|c|c|c|}
\hline \multirow{2}{*}{ Population } & \multicolumn{3}{|c|}{ ICER $\left(\right.$ ICER $\left._{A B}\right)$} \\
\hline & ICER & Median Bootstrapped ICER & Bootstrap 95\% Percentiles \\
\hline \multicolumn{4}{|l|}{ Incremental Cost per PCa Avoided } \\
\hline Biopsy & $\$ 18.76$ & $\$ 21.69$ & $\$ 14.96$ to $\$ 35.21$ \\
\hline North America & $\$ 119.18$ & $\$ 134.80$ & $\$ 63.73$ to $\$ 734.72$ \\
\hline Baseline PSA $<4.9 \mathrm{ng} / \mathrm{mL}$ & $\$ 53.77$ & $\$ 67.87$ & $\$ 42.27$ to $\$ 150.54$ \\
\hline Baseline PSA $\geq 4.9$ to $<6.8 \mathrm{ng} / \mathrm{mL}$ & $\$ 71.38$ & $\$ 79.09$ & $\$ 41.91$ to $\$ 330.94$ \\
\hline Baseline PSA $\geq 6.8 \mathrm{ng} / \mathrm{mL}$ & $\$ 47.09$ & $\$ 51.50$ & $\$ 24.61$ to $\$ 148.69$ \\
\hline \multicolumn{4}{|l|}{ Incremental Cost per QALY } \\
\hline Biopsy & $\$ 26515.79$ & $\$ 26178.53$ & $\$ 20121.79$ to $\$ 35817.95$ \\
\hline North America & $\$ 51780.04$ & $\$ 49144.28$ & $\$ 29239.45$ to $\$ 190938.52$ \\
\hline Baseline PSA $<4.9 \mathrm{ng} / \mathrm{mL}$ & $\$ 33257.08$ & $\$ 33286.40$ & $\$ 22709.88$ to $\$ 56973.40$ \\
\hline Baseline PSA $\geq 4.9$ to $<6.8 \mathrm{ng} / \mathrm{mL}$ & $\$ 24537.55$ & $\$ 24914.72$ & $\$ 16446.11$ to $\$ 42019.95$ \\
\hline Baseline PSA $\geq 6.8 \mathrm{ng} / \mathrm{mL}$ & $\$ 22391.29$ & $\$ 22621.86$ & $\$ 12805.91$ to $\$ 47302.07$ \\
\hline
\end{tabular}

ICER = incremental cost-effectiveness ratio; PCa = prostate cancer; PSA = prostate-specific antigen; $Q A L Y=$ quality-adjusted life-year.

greater in the baseline PSA $\geq 6.8 \mathrm{ng} / \mathrm{mL}$ population ( $\$ 1953$ ) than the difference seen in the biopsy population (Figure 2), whereas lower differences were found in the baseline PSA $<4.9 \mathrm{ng} / \mathrm{mL}$ ( $\$ 887$ ), the baseline PSA $\geq 4.9$ and $<6.8 \mathrm{ng} / \mathrm{mL}$ (\$990), and the North American (\$118) populations (Figure 2). The lower difference in mean total cost between the placebo group and the dutasteride group in the North American population was due to the occurrence of a lower proportion of hospitalizations and shorter lengths of stay for surgical procedures. Using the Wilcoxon rank sum test, the total costs for the dutasteride group remained significantly lower than the total costs for the placebo group in all sensitivity analysis population subgroups.

The incremental cost per QALY among the different population subgroups were consistent with a low of \$22 391 in the baseline PSA $\geq 6.8 \mathrm{ng} / \mathrm{mL}$ population and a high of $\$ 51780$ in the North American population. Similar results occurred for the incremental cost per PCa case avoided: a low of $\$ 47$ in the baseline PSA $\geq 6.8 \mathrm{ng} / \mathrm{mL}$ population and a high of $\$ 119$ in the North American population. (Note the denominators for the population subgroups were summed to comprise the denominator for the biopsy population. Thus, the incremental costs per PCa case avoided are larger for population subgroups than for the biopsy population.) Table 5 shows the ICERs.

In examining uncertainty due to sampling variation, the baseline and bootstrapped results were similar. The scatter plot and cost- effectiveness acceptability curve for the biopsy population are presented in Figure 3; dutasteride was cost-effective $100 \%$ of the time since all bootstrapped ICERs fell to the east and south of the $\$ 50000$ threshold line. Table 5 displays bootstrapped median ICERs and $95 \%$ percentiles for each population.

\section{Discussion}

We performed an economic analysis of dutasteride compared with placebo in men at increased risk for PCa within the biopsy population of the REDUCE clinical trial. Specifically, we analyzed resource utilization as recorded within the REDUCE trial and performed cost and cost-effectiveness analyses. As a result of the resource use observed in the trial, we found that, compared with patients in the dutasteride group, patients in the placebo group were at significantly higher risk for incurring resource use pertaining to concomitant medications (including alpha-blockers) and health care visits for surgical procedures, unscheduled biopsies, UTI, AUR, or macroscopic hematuria. Total costs, excluding study drug cost, were significantly higher in the placebo group than in the dutasteride group of the biopsy population and in all examined population subgroups. We observed that the use of dutasteride to reduce the risk of PCa was cost-effective compared with placebo. In addition, the cost to avoid a case of PCa was minimal. These results were observed over the 4 -year trial period. As a result, they cannot be generalized beyond this period of time. 


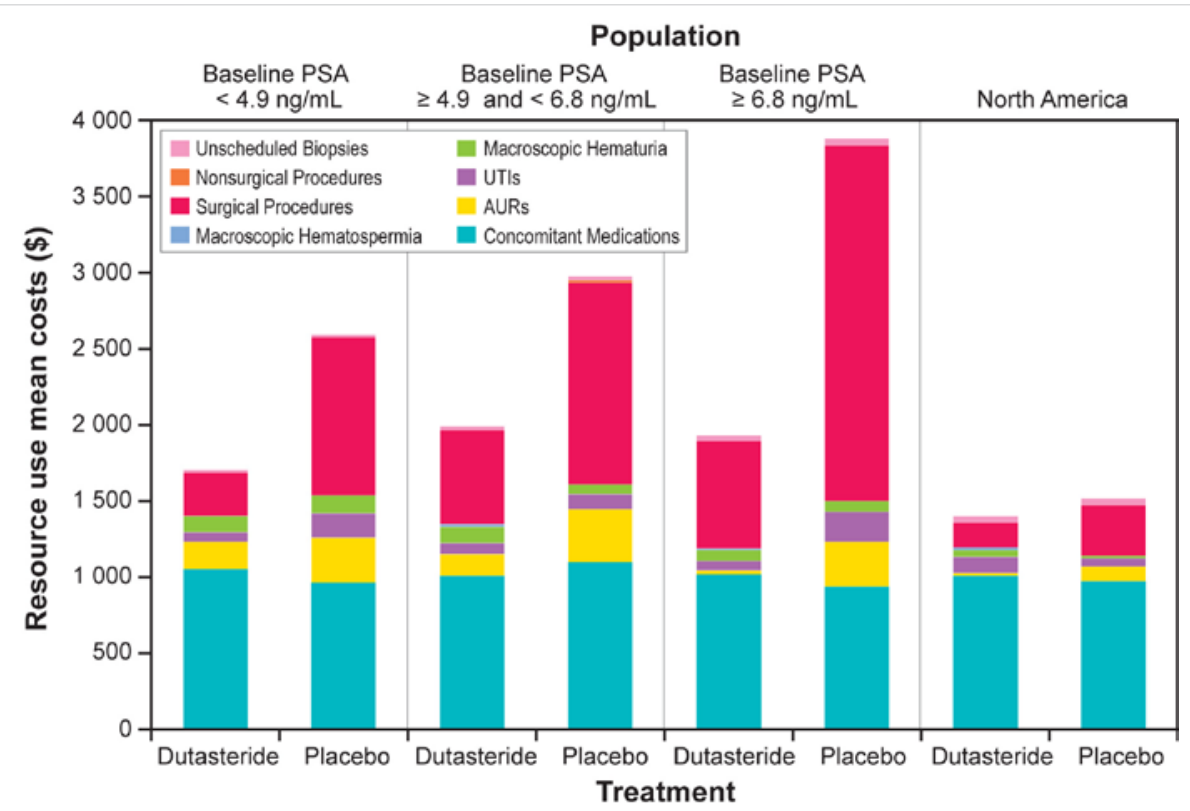

AUR = acute urinary retention; PSA = prostate-specific antigen; UTI = urinary tract infection

Figure 2: Total and Component Mean Costs in Different Populations by Treatment Groups.

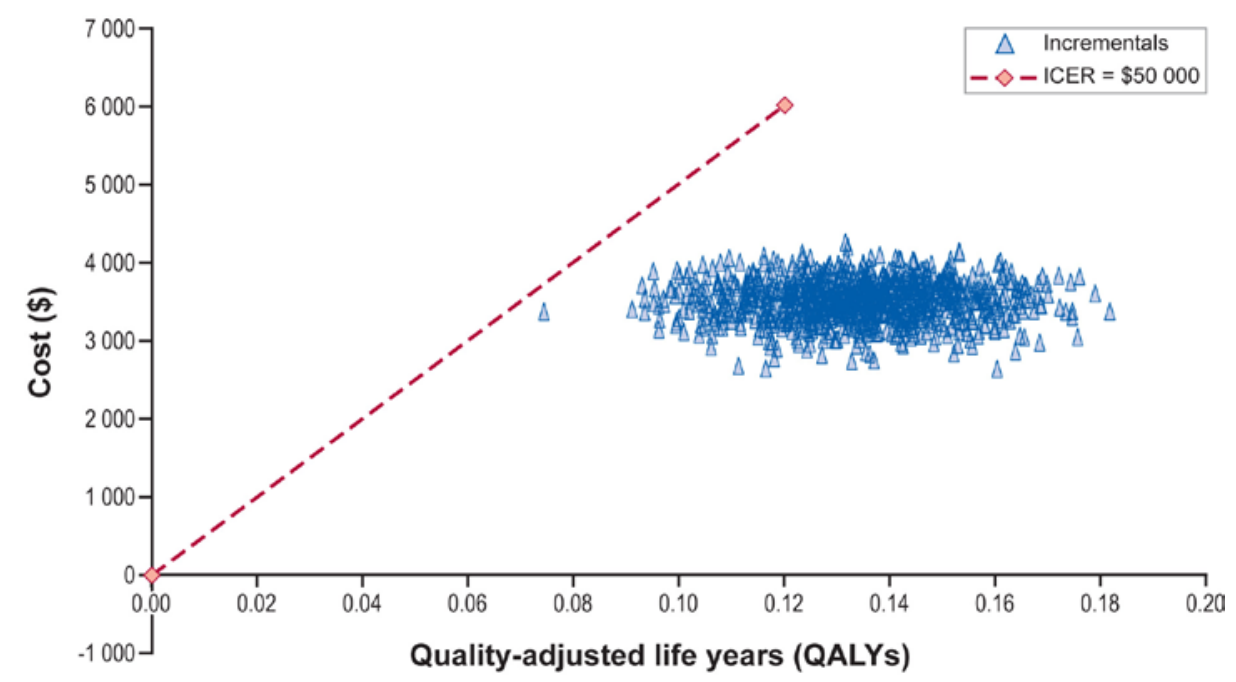

ICER =incremental cost-effectiveness ratio

Figure 3a: Probabilistic Sensitivity Analysis Results. Scatter Plot of Bootstrap Runs for Biopsy Population.

This analysis differs from previous analyses in that all previous analyses examined the impact of 5ARIs using decision analytic modeling techniques. Those techniques were used because information on the direct impact of 5ARI use on resource use was not available. In other words, decision analytic techniques were used to extrapolate the impact of 5ARI use through the compilation of data from a variety of sources because of the absence of complete data. To fully understand the impact that chemoprevention with a 5ARI would have on resource use, we would ideally prefer to collect these data as part of a real-world, prospectively designed study. However, this type of study is costly in terms of time and money. Since resource use was collected as part of the large clinical trial in this study, we felt it was important to examine the impact of dutasteride on unscheduled resource use as seen within the clinical trial and on potential costs associated with the use of these resources. Although these data were collected within a controlled setting, analyzing the unplanned resource use provides us with some sense of potential impact on these data.

In the biopsy population, the use of dutasteride was shown to reduce the proportion of patients on alpha-blocker therapy by approximately $14 \%$. However, we observed only small decreases in alpha-blocker costs in patients on dutasteride because patients in the dutasteride group taking alpha-blockers had a greater number of days on alpha-blocker therapy (mean $=1078$ days) than patients in the placebo group who were taking alpha-blockers (mean $=911$ days). Changing the imputation method may change our results to be more in favor of dutasteride. 


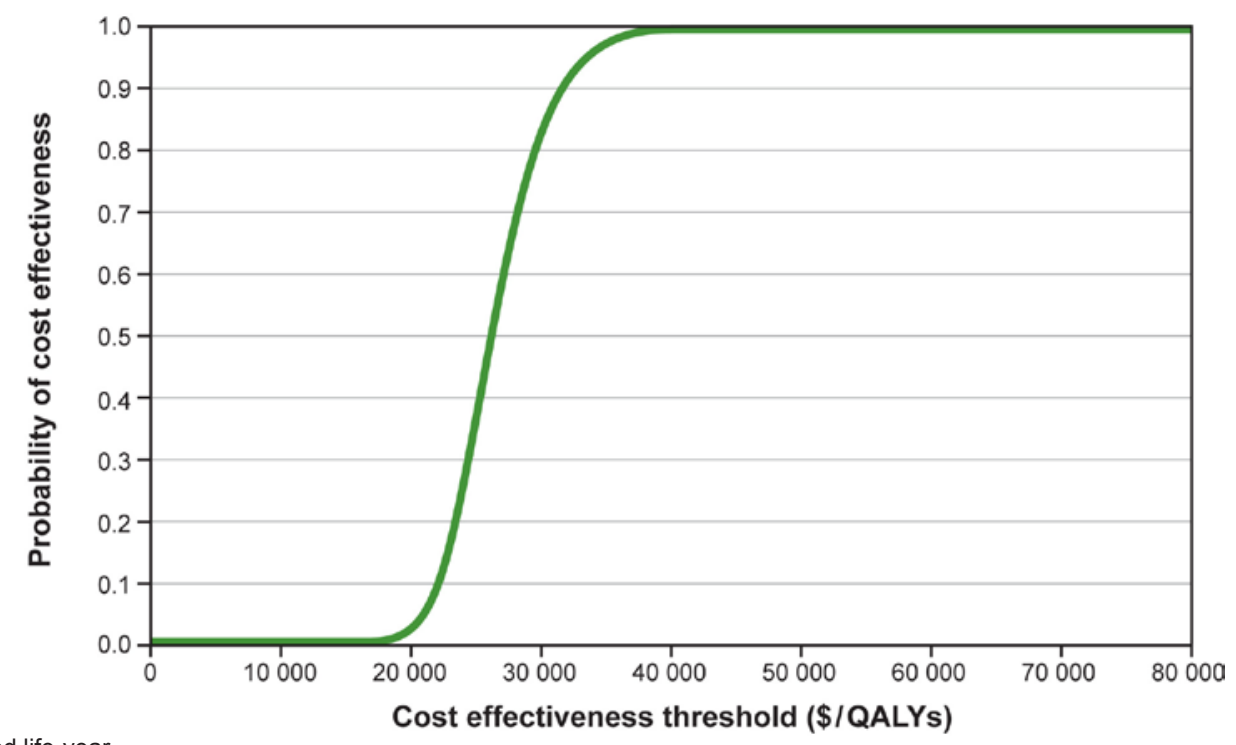

QALY = quality-adjusted life-year.

Figure 3b: Probabilistic Sensitivity Analysis Results. Cost-effectiveness Acceptability Curve of Bootstrap Runs for Biopsy Population.

This study has several limitations, particularly when making comparisons between treatments. First, this is an analysis of resource use data collected as part of a clinical trial. Patients within clinical trials are in a controlled setting and are monitored closely. We endeavored to exclude resource use that was trial driven, but we acknowledge that these data may not fully reflect resource use and costs as seen in the real world. For example, it is possible that unscheduled biopsies may be underestimated within the trial because scheduled biopsies occurred within the trial. Thus, investigators within the trial might have delayed performing biopsies they might have performed in a real-world clinical setting because they knew the patient was scheduled for a biopsy in a few months. In addition, resource use after completion of the trial was not considered.

Another limitation of this analysis is that dutasteride is currently indicated to treat $\mathrm{BPH}$. Therefore, it might be argued that most of the benefits accrued for patients in the cost-effectiveness analysis are due to treating $\mathrm{BPH}$. As a result, a limitation of the analysis to examine the cost-effectiveness of dutasteride as a chemoprevention agent is that it includes the impact that dutasteride has on preventing BPH-related events such as AURs and BPH-related surgeries. In other words, these analyses should consider only the impact on PCa-related costs. However, the incremental cost per PCa case avoided is well below the cost of treating PCa. In addition, it is important to realize that men at increased risk for PCa most likely will have BPH symptoms or be at increased risk for BPH. Thus, it is relevant to look at gains from both within the analysis.

In men who went on to have PCa, it is possible that complete resources to treat their PCa were not captured. In fact, $95 \%$ of men with PCa had less than 1 year of follow-up data within the trial setting. Thus, the full impact of potentially offsetting PCa costs was not captured within this analysis. We performed a subanalysis in which patients on each treatment who had less than 1 year follow-up after PCa diagnosis had their costs replaced with the average costs for patients on the same treatment who had 1 or more years of follow-up after diagnosis. We found an additional improvement in the cost-effectiveness, with an incremental cost per QALY of \$16342 and an incremental cost per PCa case of $\$ 7$. Thus, the baseline results of this analysis may be considered conservative compared with what we might expect to see in actual clinical practice.

This was an analysis of pooled, multicountry data. We made no adjustments for differences in resource use patterns between countries. In addition, we applied US costs to the globally collected data. In evaluating the cost and resource use differences from a US perspective, we must use caution. However, with these limitations in mind, we performed sensitivity analyses including a sensitivity analysis in which the resource use and cost were examined in a population of patients in North America. Within this subanalysis specific to North America, a higher incremental cost per QALY was observed for the North American region than for the biopsy population. Overall, we observed a lower proportion of hospitalizations and shorter lengths of stay for surgical procedures in the North American Region than in the biopsy population. Thus, the use of dutasteride as a chemoprevention agent was not as cost-effective in the North American population as in the biopsy population.

In this analysis, we did not cost and analyze all concomitant medications that were reported in the REDUCE trial. Instead, we selected specific classes of concomitant medications that we believe would impact the overall costs of health care if dutasteride were taken to reduce the risk of $\mathrm{PCa}$. This pragmatic approach was chosen to better reflect the true impact of treatments on relevant resource utilization. As a validation, medication classes that were included in the analysis were verified by a urologist as being most likely to be affected by the use of a 5ARI to reduce the risk of PCa.

Our analysis was intended to be exploratory and descriptive in nature. Because cost distributions are skewed, caution is advised when interpreting the parametrically estimated CIs, and they should be viewed as purely descriptive. Generally, it is safer to trust nonparametric conclusions because the inconsistency between parametric and nonparametric results suggests nonnormal distributions. However, one should be aware that the Wilcoxon test compares the cost distributions and not the arithmetic means. Given the exploratory nature of the 
analysis, we did not make multiple comparison adjustments; thus, $P$ values should be interpreted with caution. Future work to provide a more comprehensive picture of the impact that the use of dutasteride would have on health care costs and resource use could include the use of a study of routine clinical practice data in this area.

Overall, in the absence of a prospective study to examine the complete economic impact of the use of a 5ARI as a prostate chemoprevention agent in men at increased risk for prostate cancer, we performed an analysis of the unscheduled resource use collected within the REDUCE clinical trial. Although increased use of a dutasteride would occur within the population, decreased use of concomitant medications and various healthcare procedures may be observed. As a result, a reduction in costs of non-5ARI medications and medical resources may result. In addition, although some increases in the costeffectiveness were seen when analyzing the sensitivity populations, we may observe that the use of dutasteride may be good value for money across all populations analyzed.

\section{Acknowledgements}

The authors would like to thank Ms. Gail Zona for her careful editing of the manuscript.

Dr. Chirila, Dr. Earnshaw, Ms. McDade, Mr. Roskell, and Mr. Shannon are employees of RTI Health Solutions, an independent contract research organization that has received research funding for this and other studies from GlaxoSmithKline and pharmaceutical companies that market drugs for use as a chemoprevention for prostate cancer and other medical conditions. Dr. Black is an employee of GlaxoSmithKline, a pharmaceutical company that manufacturers dutasteride. Dr. Gerald Andriole is an employee at Washington University School of Medicine and has received consulting or advisory fees from Aeterna Zentaris, Ferring, EMD Serono, GenProbe, Onconome, Veridex, Amgen, GlaxoSmithKline, Steba Biotech and the France Foundation; equity ownership/stock from Cambridge Endo, Envisioneering Medical and Viking Medical; lecture fees from GlaxoSmithKline; and grant support from Aeterna Zentaris. Dr. Francesco Montorsi is a professor of Urology at Universitá Vita Salute San Raffaele and has received research funding for this and other studies and from other pharmaceutical companies that market drugs for the treatment for patients with prostate cancer.

\section{References}

1. American Cancer Society (2010) Cancer Facts and Figures 2010. Atlanta Cancer Society, Atlanta, GA.

2. Mariotto AB, Yabroff KR, Shao Y, Feuer EJ, Brown ML (2011) Projections of the cost of cancer care in the United States: 2010-2020. J Natl Cancer Inst 103: 117-128.

3. Thompson IM, Goodman PJ, Tangen CM, Lucia MS, Miller GJ, et al. (2003) The influence of finasteride on the development of prostate cancer. $\mathrm{N} \mathrm{Engl} J$ Med 349: 215-224.

4. Andriole GL, Bostwick DG, Brawley OW, Gomella LG, Marberger M, et al. (2010) Effect of dutasteride on the risk of prostate cancer. N Engl J Med 362 : 1192-1202.

5. Earnshaw SR, McDade CL, Black LK, Bell CF, Kattan MW (2010) Cos effectiveness of 5-alpha reductase inhibitors for the prevention of prostate cancer in multiple patient populations. Pharmacoeconomics 28: 489-505.

6. Kattan MW, Earnshaw SR, McDade CL, Black LK, Andriole GL (2011) Costeffectiveness of chemoprevention for prostate cancer with dutasteride in a high risk population based on results from the REDUCE Clinical Trial. Appl Health Econ Health Policy 9: 305-315.

7. Zeliadt SB, Etzioni RD, Penson DF, Thompson IM, Ramsey SD (2005) Lifetime implications and cost-effectiveness of using finasteride to prevent prostate cancer. Am J Med 118: 850-857.

8. Svatek RS, Lee JJ, Roehrborn CG, Lippman SM, Lotan Y (2006) The cost of prostate cancer chemoprevention: a decision analysis model. Cancer Epidemiol Biomarkers Prev 15: 1485-1489.

This article was originally published in a special issue, Cancer

Chemoprevention handled by Editor(s). Dr. Rajendra Sharma, University of North Texas, USA
9. Svatek RS, Lee JJ, Roehrborn CG, Lippman SM, Lotan Y (2007) Erratum: the cost of prostate cancer chemoprevention: a decision analysis model. Cancer Epidemiol Biomarkers Prev 16: 1042.

10. Svatek RS, Lee JJ, Roehrborn CG, Lippman SM, Lotan Y (2008) Costeffectiveness of prostate cancer chemoprevention: a quality of life-years analysis. Cancer 112: 1058-1065

11. Svatek RS, Lotan Y (2011) Cost utility of prostate cancer chemoprevention with dutasteride in men with an elevated prostate specific antigen. Cancer Prev Res (Phila.) 4: 277-283.

12. HCUPnet (2006) Healthcare Cost and Utilization Project. Agency for Healthcare Research and Quality, Rockville, MD. Accessed November 29, 2010.

13. Friedman B, La Mare J, Andrews R, McKenzie DH (2002) Practical options for estimating cost of hospital inpatient stays. J Health Care Finance 29: 1-13.

14. American Medical Association (2008) Current Procedural Terminology. CPT 2001. AMA Press, Chicago, IL.

15. Ingenix, Inc (2008) The Essential RBRVS: a Comprehensive Listing of RBRVS Values for CPT and HCPCS Codes. St. Anthony Publishing, New York.

16. Red Book for Windows. Version 61127 (CD-ROM) (2010) Thomson Healthcare Greenwood Village, CO.

17. Ackerman SJ, Rein AL, Blute M, Beusterien K, Sullivan EM (2000) Cost effectiveness of microwave thermotherapy in patients with benign prostatic hyperplasia: part 1-methods. Urology 56: 972-980.

18. Brenmer KE, Chong CA, Tomlinson G, Alibhai SM, Krahn MD (2007) A review and meta-analysis of prostate cancer utilities. Med Decis Making 27: 288-298.

19. Mittmann N, Trakas K, Risebrough N, Liu BA (1999) Utility scores for chronic conditions in a community dwelling population. Pharmacoeconomics 15: 369 376

20. Barber JA, Thompson SG (1998) Analysis and interpretation of cost data in randomized controlled trials: review of published studies. BMJ 317: 1195-1200.

21. Rothman KJ (1990) No adjustments are needed for multiple comparisons Epidemiology 1: 43-46

22. Eichler HG, Kong SX, Gerth WC, Mavros P, Jönsson B (2004) Use of costeffectiveness analysis in health-care resource allocation decision-making: how are cost-effectiveness thresholds expected to emerge? Value Health 7: 518 528.

23. Hirth RA, Chernew ME, Miller E, Fendrick AM, Weissert WG (2000) Willingness to pay for a quality-adjusted life year: in search of a standard. Med Decis Making 20: 332-342.

24. Weinstein MC (1995) From cost-effectiveness ratios to resource allocation: where to draw the line In: Sloan FA editor. Valuing Health Care: Costs, Benefits, and Effectiveness of Pharmaceuticals and Other Medical Technologies. Cambridge University Press, New York.

25. Gray A, Raikou M, McGuire A, Fenn P, Stevens R, et al. (2000) Costeffectiveness of an intensive blood glucose control policy in patients with type 2 diabetes: economic analysis alongside randomized controlled trial (UKPDS 41). United Kingdom Prospective Diabetes Study Group. BMJ 320: 1373-1378.

26. Lothgren M, Zethraeus N (2000) Definition, interpretation and calculation of cost-effectiveness acceptability curves. Health Econ 9: 623-630. 